\title{
Structural and relative stabilities, electronic properties and possible reactive routing of osmium and ruthenium borides from first-principles calculations $\uparrow$
}

\author{
Yachun Wang, ${ }^{a}$ Tiankai Yao, ${ }^{a}$ Li-Min Wang, ${ }^{a}$ Jinlei Yao, ${ }^{b, c}$ Hui Li, ${ }^{a}$ Jingwu Zhang *a \\ and Huiyang Gou*a,d,e
}

\begin{abstract}
First-principles calculations are employed to provide a fundamental understanding of the structural features and relative stability, mechanical and electronic properties and possible reactive route for osmium and ruthenium borides. The structural searches and calculations of the formation enthalpy identify a low-energy monoclinic phase for $\mathrm{OsB}_{3}$ with $P 2_{1} / m$ symmetry, an orthorhombic phase for $\mathrm{OsB}_{4}$ with Pmmn symmetry, an orthorhombic phase for $\mathrm{RuB}_{3}$ with Pnma symmetry and a hexagonal phase for $\mathrm{RuB}_{4}$ with $P 6_{3} / m m c$ symmetry. Also, the structure transition at high pressure is also predicted for $\mathrm{MB}_{3}$ and $\mathrm{MB}_{4}$ $\left(\mathrm{M}=\mathrm{Os}\right.$ and $\mathrm{Ru}$ ). Moreover, among the borides, orthorhombic $\mathrm{RuB}_{3}$ and $\mathrm{OsB}_{4}$ phases are predicted to be potential hard materials with estimated Vickers hardness values of 26.3 and $31.3 \mathrm{GPa}$, respectively. The analysis on the electronic properties and crystal orbital Hamilton population shows that the directional boron-boron networks, together with the strong metal-boron bonds, are responsible for their excellent mechanical properties. Relative enthalpy calculations with respect to possible constituents are also investigated to assess the prospects for phase formation and an attempt at high-pressure synthesis is suggested to obtain osmium and ruthenium tri- and tetra-borides.
\end{abstract}

Received 5th December 2012, Accepted 25th February 2013

DOI: $10.1039 / c 3 d t 32918 f$

www.rsc.org/dalton which can be used as a guide to optimize the mechanical properties through fine tuning the boron concentrations in these TM borides.

Recently, osmium di-boride $\left(\mathrm{OsB}_{2}\right)$ was synthesized at ambient conditions ${ }^{9}$ and the incorporation of boron into the osmium lattice gives rise to a significant enhancement of the Vickers hardness (from $4 \mathrm{GPa}$ for Os to $20 \mathrm{GPa}$ for $\mathrm{OsB}_{2}$ ). Furthermore, OsB and $\mathrm{Os}_{2} \mathrm{~B}_{3}$ were prepared by arc melting and subsequent annealing at ambient pressure and the related mechanical properties were investigated. ${ }^{10,11}$ In the $\mathrm{Ru}-\mathrm{B}$ system, $\mathrm{Ru}_{7} \mathrm{~B}_{3}, \mathrm{RuB}, \quad \mathrm{Ru}_{2} \mathrm{~B}_{3}$ and $\mathrm{RuB}_{2}$ were obtained experimentally. ${ }^{10-12}$ The combination of noticeable mechanical properties and the low-cost synthesis condition suggests that Os and $\mathrm{Ru}$ borides may be good candidates for hard materials. Nevertheless, limited information on these borides with a high boron content is available both theoretically and experimentally. The $\mathrm{OsB}_{3}$ phase with the space group $P \overline{6} m 2$ was predicted using the USPEX code. ${ }^{13}$ Additionally, Zhang et $a l .{ }^{14}$ predicted an orthorhombic $P m m n \mathrm{OsB}_{4}$ phase with a theoretical Vickers hardness of $28 \mathrm{GPa}$ using the CALYPSO code. ${ }^{15}$ For $\mathrm{Ru}$ borides, $\mathrm{RuB}_{4}$ with a Pnnm structure was also theoretically investigated. ${ }^{16}$ These results show that the introduction of more boron further strengthens the mechanical properties of Os borides. Although progress has been made to find the possible stable structures for Os and $\mathrm{Ru}$ borides, 
systematical comparisons between different predictions are still sparse because their properties can completely alter with the presence of new structures. Moreover, in Os-B and $\mathrm{Ru}-\mathrm{B}$ systems, for now we have a lack of knowledge of the reliable physical properties of all competing phases compared with previous borides and a clear picture of how to tune or control the mechanical properties to obtain compounds with higher boron concentrations. Therefore, a more detailed exploration of the structural features, relative stabilities and mechanical properties of borides, especially those with a high boron content, in Os-B and $\mathrm{Ru}-\mathrm{B}$ systems is of great importance for potential technological applications. Furthermore, attempting to synthesize the predicted new compounds remains difficult and challenging in experiments and a possible synthesis route can help to further actual realization in the laboratory.

In this paper, we systematically explore the crystal structure, relatively stability and electronic structure of $\mathrm{M}_{7} \mathrm{~B}_{3}, \mathrm{MB}, \mathrm{M}_{2} \mathrm{~B}_{3}$, $\mathrm{MB}_{2}, \mathrm{MB}_{3}$ and $\mathrm{MB}_{4}(\mathrm{M}=\mathrm{Os}$ and $\mathrm{Ru})$ to present a thorough understanding of Os-B and $\mathrm{Ru}-\mathrm{B}$ systems. Additionally, possible synthesizing routes for $\mathrm{MB}_{3}$ and $\mathrm{MB}_{4}$ from their constituent elements and/or compounds are probed. Furthermore, the dynamic stability of the potential ground states found for $\mathrm{MB}_{3}$ and $\mathrm{MB}_{4}$ are studied by phonon dispersion. Also, their elastic moduli are calculated and their theoretical hardness is predicted. Finally, their structural features and bonding situations are analyzed from the electronic structure, distributions of electron density and crystal orbital Hamilton population (COHP). Therefore, the present results could provide a theoretical prerequisite for the experimental synthesis and technological applications of osmium and ruthenium borides.

\section{Computational details}

In the present work, the experimentally determined structures, $\mathrm{Ru}_{7} \mathrm{~B}_{3}$ (No. 186, $P 6_{3} m c$ ), ${ }^{17}$ OsB (No. 187, $\left.P \overline{6} m 2\right)^{10}$ and hexagonal $\mathrm{Ru}_{2} \mathrm{~B}_{3}$ (No. 194, $\left.P 6_{3} / m m c\right)^{18}$ structures were selected for $\mathrm{M}_{7} \mathrm{~B}_{3}$, $\mathrm{MB}$ and $\mathrm{M}_{2} \mathrm{~B}_{3}$, respectively. For $\mathrm{MB}_{2}$, besides the experimentally examined orthorhombic $\mathrm{OsB}_{2}$ (No. 59, Pnma), ${ }^{10}$ the $\mathrm{ReB}_{2}$ (No. 194, $\left.\mathrm{P6}_{3} / \mathrm{mmc}\right)^{4}$ structure was also considered (denoted as 59- and 194- $\mathrm{MB}_{2}$, respectively, hereafter). For $\mathrm{MB}_{3}$ and $\mathrm{MB}_{4}$, since no experimental structural results have been determined to date, we thus considered the predicted structures via the $a b$ initio evolutionary algorithm in ref. 13 and 14 as well as some other possible structures. The orthorhombic $\mathrm{TcP}_{3}$ (No. 62, Pnma), ${ }^{19} \mathrm{FeB}_{3}$ (No. 11, $P 2_{1} / m$ ) ${ }^{20}$ and rhombohedral $\mathrm{MoB}_{3}$ (No. 166, $R \overline{3} m)^{7}$ structures were considered for the $\mathrm{MB}_{3}$ phases (designated as 62-, 11- and $166-\mathrm{MB}_{3}$, respectively, hereafter). For the $\mathrm{MB}_{4}$ phases, five possible structures were adopted here, orthorhombic $\mathrm{OsB}_{4}$ (No. 59, Pmmn), ${ }^{14}$ hexagonal $\mathrm{MoB}_{4}$ (No. 194, $\mathrm{P6}_{3} / \mathrm{mmc}, Z=2$ ), ${ }^{7}$ orthorhombic oI10-FeB 4 (No. 71, Immm), ${ }^{19}$ and $\mathrm{CrB}_{4}$ (No. 58, Pnnm) ${ }^{15}$ (designated as 59-, 194-, 71- and $58-\mathrm{MB}_{4}$, respectively, hereafter), together with $\mathrm{WB}_{4}{ }^{-}$ type (No. $\left.194, \mathrm{P6}_{3} / \mathrm{mmc}, Z=4\right){ }^{21}$

Geometry optimization was performed using the CASTEP $\operatorname{code}^{22}$ within the generalized gradient approximation of
Perdew, Burke and Ernzerhof (GGA-PBE). ${ }^{23}$ The optimization of the structural parameters and atomic positions were realized by minimizing the forces and stress tensors, and the interactions between the ions and the electrons of $\mathrm{M}$ and $\mathrm{B}$ were expressed by a Vanderbilt ultrasoft pseudopotential. ${ }^{24}$ The cutoff energy of the atomic wave functions was set to be $400 \mathrm{eV}$ and the $k$ points, $8 \times 8 \times 6,10 \times 10 \times 10,10 \times 10 \times 4$, $10 \times 10 \times 6$ and $10 \times 10 \times 6$ were selected for $M_{7} B_{3}, M B, M_{2} B_{3}$, $59-\mathrm{MB}_{2}$ and $194-\mathrm{MB}_{2}$, respectively. A $10 \times 10 \times 10 \mathrm{k}$ point and cutoff energy of $450 \mathrm{eV}$ were used for all the considered $\mathrm{MB}_{3}$ and $\mathrm{MB}_{4}$ phases to be precise enough for good energy convergence. Within each self-consistency cycle, the total energy was converged to be within $10^{-7} \mathrm{eV}$. The formation enthalpy of these borides was estimated by the following equation, ${ }^{25} \Delta H_{\mathrm{f}}=$ $\left[E_{\text {total }}\left(\mathrm{M}_{x} \mathrm{~B}_{y}\right)-\left(x E_{\text {total }}(\mathrm{M})+y E_{\text {total }}(\mathrm{B})\right)\right] /(x+y)(\mathrm{M}=$ Os and $\mathrm{Ru})$, where $E_{\text {total }}\left(\mathrm{M}_{x} \mathrm{~B}_{y}\right)$ is the obtained total energies for the considered borides at equilibrium volume, $E_{\text {total }}(\mathrm{M})$ and $E_{\text {total }}(\mathrm{B})$ are the total energy of the pure hexagonal metal and the most stable allotrope of crystalline boron $(\alpha-B)$ at zero pressure, respectively. The polycrystal elastic moduli have been estimated via a Voight-Reuss-Hill (VRH) approximation. ${ }^{26}$

To gain further information on the chemical bonding of the present $\mathrm{MB}_{3}$ and $\mathrm{MB}_{4}$ phases, we performed tight-bonding linear muffin-tin orbital computations with the aid of an atomic sphere approximation (ASA) (TB-LMTO-ASA program). ${ }^{27}$ Then, the calculated COHP and density of state (DOS), weighted by the corresponding Hamilton matrix elements from the self consistent LMTO wave function, were presented by plotting -COHP $(E)$ curves, where positive and negative values stand for bonding and anti-bonding states, respectively. The Fermi levels have been set to zero energy.

\section{Results and discussion}

\subsection{Structure features}

The optimized equilibrium lattice parameters, relative total energy and the whole set of single crystal elastic constants $\left(C_{i j}\right)$ for the considered Os and Ru borides are listed in Table 1. The obtained lattice parameters of $\mathrm{Ru}_{7} \mathrm{~B}_{3}, \mathrm{MB}, \mathrm{M}_{2} \mathrm{~B}_{3}$ and $59-\mathrm{MB}_{2}$ $(\mathrm{M}=\mathrm{Os}$ and $\mathrm{Ru})$ are in good agreement with the available experimental results, ${ }^{10,17,18}$ verifying the reliability of the calculation here. The obtained elastic constants of the studied structures are found to satisfy the Born-Huang mechanical stability criteria, ${ }^{28-30}$ indicating their mechanical stabilities.

To gain systematical comprehension of the structural features, the optimized structures of $M_{7} B_{3}, M B$ and $M_{2} B_{3}$ as well as 59- and $194-\mathrm{MB}_{2}(\mathrm{M}=\mathrm{Os}$ and $\mathrm{Ru}$ ) are shown in Fig. 1 (for more the detailed bonding lengths in these compounds, please refer to the ESI $\dagger$ ). The $\mathbf{M}_{7} \mathrm{~B}_{3}$ structure (Fig. 1a) has a densely packed metal skeleton mainly composed of $\mathbf{M}$ tetrahedra and octahedra, while the $\mathrm{B}$ atoms occupy trigonal prism voids between the $\mathrm{M}$ tetrahedra and octahedra. ${ }^{17}$ In this structure, the low B concentration fails to cut off the connection between the metal atoms (Fig. 1f). Therefore, there are still a large amount of $\mathrm{M}-\mathrm{M}$ bonds whose distances are only slightly 
Table 1 Calculated equilibrium lattice parameters, $a_{0}(\AA), b_{0}(\AA), c_{0}(\AA)$, the difference in total energy, $\Delta E(e V)$ and elastic constants $C_{i j}$ for the Os-B and Ru-B system

\begin{tabular}{|c|c|c|c|c|c|c|c|c|c|c|c|c|c|}
\hline & & $a_{0}$ & $b_{0}$ & $c_{0}$ & $\Delta E$ & $C_{11}$ & $C_{22}$ & $C_{33}$ & $C_{44}$ & $C_{55}$ & $C_{66}$ & $C_{12}$ & $C_{13}$ \\
\hline $\mathrm{Os}_{7} \mathrm{~B}_{3}$ & GGA & 7.558 & & 4.801 & & 487 & & 559 & 89 & & & 303 & 226 \\
\hline \multirow[t]{2}{*}{ OsB } & GGA & 2.892 & & 2.877 & & 615 & & 808 & 190 & & & 201 & 175 \\
\hline & Exp. $^{a}$ & 2.876 & & 2.871 & & $618^{b}$ & & 791 & 188 & & & 196 & 191 \\
\hline \multirow[t]{2}{*}{$\mathrm{Os}_{2} \mathrm{~B}_{3}$} & GGA & 2.912 & & 12.777 & & 528 & & 865 & 209 & & & 186 & 189 \\
\hline & Exp. $^{a}$ & 2.909 & & 12.945 & & & & & & & & & \\
\hline \multirow[t]{2}{*}{$59-\mathrm{OsB}_{2}$} & GGA & 4.696 & & 4.094 & 0 & 549 & 538 & 744 & 77 & 203 & 199 & 164 & 183 \\
\hline & Exp. $^{a}$ & 4.686 & & 4.082 & & $546^{b}$ & 553 & 763 & 64 & 209 & 207 & 183 & 198 \\
\hline $194-\mathrm{OsB}_{2}$ & GGA & 2.938 & & 7.325 & 0.02 & 453 & & 870 & 206 & & & 183 & 218 \\
\hline $11-\mathrm{OsB}_{3}$ & GGA & 4.051 & 2.899 & 5.934 & 0 & 674 & 525 & 584 & 135 & 291 & 128 & 97 & 247 \\
\hline $62-\mathrm{OsB}_{3}$ & GGA & 10.096 & 2.883 & 4.703 & 0.11 & 543 & 538 & 501 & 244 & 229 & 187 & 113 & 245 \\
\hline \multirow[t]{2}{*}{$187-\mathrm{OsB}_{3}$} & GGA & 2.8952 & & 4.609 & 0.17 & 519 & & 733 & 189 & & & 126 & 219 \\
\hline & $\mathrm{GGA}^{c}$ & 2.903 & & 4.616 & & 525 & & 751 & 186 & & & 125 & 221 \\
\hline $166-\mathrm{OsB}_{3}$ & GGA & 5.287 & & 9.072 & 0.35 & & & & & & & & \\
\hline \multirow[t]{2}{*}{$59-\mathrm{OsB}_{4}$} & GGA & 7.104 & 2.886 & 4.006 & 0 & 610 & 573 & 632 & 151 & 342 & 180 & 130 & 245 \\
\hline & $\mathrm{GGA}^{d}$ & 7.119 & 2.896 & 4.015 & & 612 & 576 & 630 & 152 & 349 & 178 & 128 & 245 \\
\hline $194-\mathrm{OsB}_{4}$ & GGA & 2.957 & & 10.665 & 0.2 & 449 & & 900 & 152 & & & 147 & 177 \\
\hline $58-\mathrm{OsB}_{4}$ & GGA & 4.711 & 5.552 & 3.229 & 0.78 & & & & & & & & \\
\hline $71-\mathrm{OsB}_{4}$ & GGA & 4.698 & 3.289 & 5.547 & 0.81 & & & & & & & & \\
\hline \multirow[t]{2}{*}{$\mathrm{Ru}_{7} \mathrm{~B}_{3}$} & GGA & 7.497 & & 4.731 & & 401 & & 374 & 94 & & & 178 & 164 \\
\hline & Exp. ${ }^{e}$ & 7.463 & & 4.714 & & & & & & & & & \\
\hline \multirow[t]{2}{*}{ RuB } & GGA & 2.866 & & 2.855 & & 505 & & 704 & 160 & & & 189 & 160 \\
\hline & Exp. $^{a}$ & 2.851 & & 2.855 & & & & & & & & & \\
\hline \multirow[t]{2}{*}{$\mathrm{Ru}_{2} \mathrm{~B}_{3}$} & GGA & 2.917 & & 12.801 & & 468 & & 787 & 190 & & & 189 & 152 \\
\hline & Exp. ${ }^{f}$ & 2.905 & & 12.812 & & & & & & & & & \\
\hline \multirow[t]{2}{*}{$59-\mathrm{RuB}_{2}$} & GGA & 4.662 & & 4.052 & 0 & 521 & 455 & 705 & 104 & 217 & 177 & 175 & 151 \\
\hline & Exp. $^{a}$ & 4.645 & & 4.045 & & $518^{g}$ & & 687 & 99 & & & 183 & 164 \\
\hline 194-RuB2 & GGA & 2.918 & & 7.272 & 0.02 & 453 & & 822 & 203 & & & 188 & 156 \\
\hline $62-\mathrm{RuB}_{3}$ & GGA & 4.033 & 2.894 & 5.857 & 0 & 497 & 462 & 471 & 224 & 219 & 187 & 111 & 229 \\
\hline $11-\mathrm{RuB}_{3}$ & GGA & 9.996 & 2.866 & 4.696 & 0.07 & & & & & & & & \\
\hline $187-\mathrm{RuB}_{3}$ & GGA & 2.899 & & 4.565 & 0.12 & 435 & & 641 & 181 & & & 129 & 207 \\
\hline $166-\mathrm{RuB}_{3}$ & GGA & 5.261 & & 8.999 & 0.58 & & & & & & & & \\
\hline $194-\mathrm{RuB}_{4}$ & GGA & 2.943 & & 10.59 & 0 & 442 & & 830 & 162 & & & 150 & 152 \\
\hline $59-\mathrm{RuB}_{4}$ & GGA & 7.059 & 2.872 & 3.988 & 0.17 & & & & & & & & \\
\hline \multirow[t]{2}{*}{$58-\mathrm{RuB}_{4}$} & GGA & 4.752 & 5.53 & 3.124 & 0.57 & 384 & 789 & 309 & 114 & 164 & 191 & 167 & 202 \\
\hline & $\mathrm{GGA}^{h}$ & & & & & 390 & 785 & 338 & 97 & 179 & 188 & 171 & 195 \\
\hline 71-RuB 4 & GGA & 5.519 & 3.192 & 4.754 & 0.65 & & & & & & & & \\
\hline
\end{tabular}

${ }^{a}$ Ref. 10. ${ }^{b}$ Ref. $35 .{ }^{c}$ Ref. $13 .{ }^{d}$ Ref. $14 .{ }^{e}$ Ref. $17 .{ }^{f}$ Ref. $18 .{ }^{g}$ Ref. $36 .{ }^{h}$ Ref. 16.

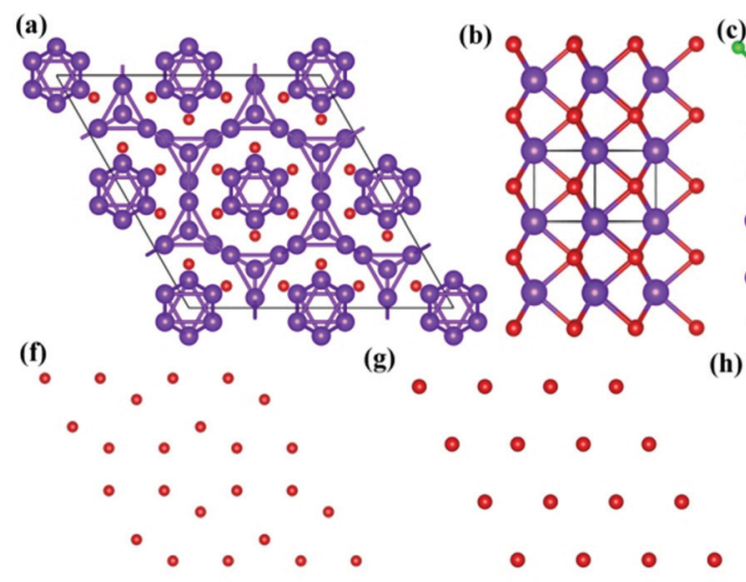

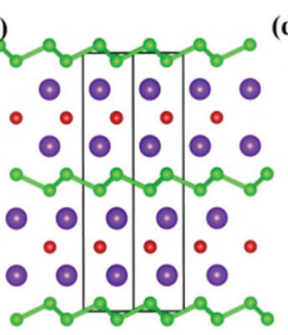

(h)

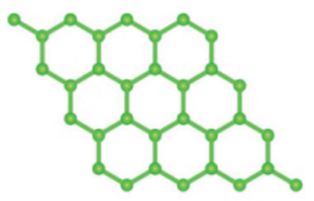

(d)

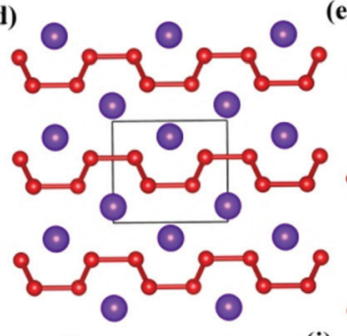

(e)

(i)

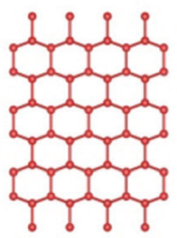

(j)
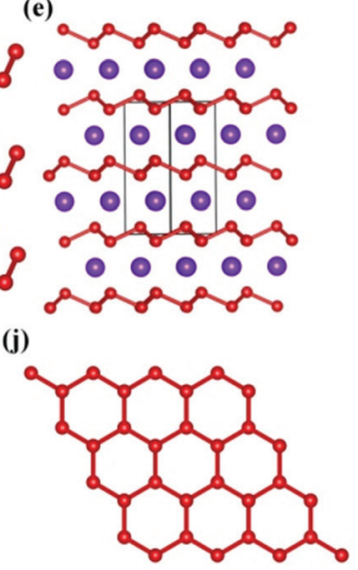

Fig. 1 Crystal structure for $M_{7} B_{3}(a), M B(b), M_{2} B_{3}(c), 59-M B_{2}(d), 194-M B_{2}(e)$ and the corresponding configuration of the $B$ layers appears ( $\left.f-j\right)$ in these structures. The large purple spheres represent $M$ atoms and the small green and red spheres represent $B$ atoms.

greater than that of the pure metal, e.g. 2.731-2.901 ${ }^{\left(\mathrm{Os}_{7} \mathrm{~B}_{3}\right)}$ vs. $2.689 \AA$ (Os), which may reserve its relatively high bulk modulus and low shear modulus, almost the same as metal
Os. Furthermore, there are no directional B-B bonds in this structure. For $\mathrm{MB}, \mathrm{M}_{2} \mathrm{~B}_{3}, 59-\mathrm{MB}_{2}$ and $194-\mathrm{MB}_{2}$, a common feature is the alternately stacking $\mathrm{M}$ and $\mathrm{B}$ layers along the 
c-axis. In MB (Fig. 1b), the B atoms are situated at the center of trigonal $\mathrm{M}$ prisms and zig-zag tri-chains of $\mathrm{M}-\mathrm{B}$ bonds form along the $c$-axis, giving rise to a particularly strong covalent $\mathrm{M}-\mathrm{B}$ bond and thus corresponds to its high incompressibility along the $c$-axis. ${ }^{10}$ Due to the long distances between the $\mathrm{B}$ atoms (exceeding $2.87 \AA$ ), no directional B-B bonds are formed either in or between the flat B layers of MB (Fig. 1g), in line with the COHP results reported in ref. 11. On adding more $\mathrm{B}$ to form $\mathrm{M}_{2} \mathrm{~B}_{3}$ (Fig. 1c), the directional $\mathrm{B}-\mathrm{B}$ bonds appear within puckered B layers (Fig. 1h). The B atoms (green) within the puckered layers are seven-coordinate with three $\mathrm{B}-\mathrm{B}$ bonds (1.872 $\AA$ for $\mathrm{Os}_{2} \mathrm{~B}_{3}$ and $1.857 \AA$ for $\mathrm{Ru}_{2} \mathrm{~B}_{3}$ ) and four M-B bonds. Nevertheless, the $\mathrm{B}$ atoms (red) in the flat layers remains the same as those in $\mathrm{MB}$ (Fig. 1g), coordinated by six $\mathrm{M}$ atoms at the corners of trigonal prisms. The $\mathrm{M}-\mathrm{B}$ distances in $\mathrm{M}_{2} \mathrm{~B}_{3}$ are slightly greater than those of $\mathrm{MB}\left(2.215 \AA\left(\mathrm{Os}_{2} \mathrm{~B}_{3}\right)\right.$ vs. $2.204 \AA$ (OsB) and $2.197 \AA\left(\mathrm{Ru}_{2} \mathrm{~B}_{3}\right)$ vs. 2.185 $\AA$ (RuB)). With this change in the trend of the $B$ layers in hand, we then wondered whether all the B layers will evolve into a puckered configuration if the B content is further increases. This speculation indeed proves to be the case. Such a structure has been found to exist in 194-symmetry (Fig. 1e). All the B atoms have the same coordination as those of the green $B$ atoms in $M_{2} B_{3}$ (Fig. 1j), with shorter $\mathrm{B}-\mathrm{B}$ distance (1.861 $\AA$ for $\mathrm{OsB}_{2}$ and $1.844 \AA$ for $\mathrm{RuB}_{2}$ ) but longer $\mathrm{M}-\mathrm{B}$ bonding $\left(2.230 \AA\right.$ for $\mathrm{OsB}_{2}$ and $2.218 \AA$ for $\mathrm{RuB}_{2}$ ) than that of $\mathrm{M}_{2} \mathrm{~B}_{3}$. However, as indicated by its positive energy with respect to $59-\mathrm{MB}_{2}, 194-\mathrm{MB}_{2}$ is energetically unfavorable but turns out to be a high pressure phase of $59-\mathrm{MB}_{2}$, which will be discussed later. For $59-\mathrm{MB}_{2}$, B layers composed of hexagonal boat-like rings (Fig. 1d) are alternately stacking with folding $\mathrm{M}$ layers along the $c$ direction. The $\mathrm{B}$ atoms also have sevenfold coordination $(3 \mathrm{~B}+4 \mathrm{M})$ with $\mathrm{B}-\mathrm{B}$ distances of 1.817-1.908 $\AA$ for $59-\mathrm{OsB}_{2}$ and 1.816-1.887 $\AA$ for $59-\mathrm{RuB}_{2}$ (Fig. 1i). Differing from the MB structure, the covalent $\mathrm{M}-\mathrm{B}$ bonds and directional $\mathrm{B}-\mathrm{B}$ bonds both contribute to the zig-zag tri-chains along the $c$-axis in $\mathrm{M}_{2} \mathrm{~B}_{3}$ and 194- $\mathrm{MB}_{2}$. Nevertheless, there is still no directional $\mathrm{B}-\mathrm{B}$ bond between the adjacent B layers in these phases.

Among all the considered structures for $\mathrm{MB}_{3}$, the results of calculations for the total energy suggest that $\mathrm{OsB}_{3}$ and $\mathrm{RuB}_{3}$ have different potential ground state structures, possessing monoclinic $P 2_{1} / m$ symmetry $\left(11-\mathrm{OsB}_{3}\right)$ and orthorhombic Pnma symmetry $\left(62-\mathrm{RuB}_{3}\right)$, respectively. Note that $11-\mathrm{OsB}_{3}$ is energetically more favorable than the previously proposed hexagonal $P \overline{6} m 2$ structure. Similarly, the hexagonal $P 6_{3} / m m c$ structure $\left(194-\mathrm{RuB}_{4}\right)$ is uncovered with the lowest total energy, favored over the previous prediction for orthorhombic $\mathrm{RuB}_{4} \cdot{ }^{16}$ To further check the dynamic stability of the newly predicted low-energy structures, the phonon spectra are presented in Fig. 2. The absence of imaginary frequencies in the Brillouin Zone suggests that the predicted structures for $\mathrm{MB}_{3}(\mathrm{M}=\mathrm{Os}$ and $\mathrm{Ru}$ ) and $194-\mathrm{RuB}_{4}$ are dynamically stable.

To obtain further structure features of $\mathrm{MB}_{3}$ and $\mathrm{MB}_{4}(\mathrm{M}=$ Os and $\mathrm{Ru}$ ), the crystal structures of the potential ground state structures are illustrated in Fig. 3. Contrary to the puckered two-dimensional boron layers of the $59-\mathrm{OsB}_{2}$ phase, a three- dimensional (3D) B network forms in the $62-\mathrm{RuB}_{3}, 11-\mathrm{OsB}_{3}$ and $59-\mathrm{OsB}_{4}$ structures and $\mathrm{M}$ atoms locate at the channels of the $\mathrm{B}$ network (Fig. 3a-c, respectively). In $62-\mathrm{RuB}_{3}$, the honeycomb ring in the $\mathrm{B}$ layer ( $b c$ plane) (Fig. 3e) resembles the counterpart $\mathrm{B}$ layer in $59-\mathrm{OsB}_{2}$ but with a much greater degree of undulation. These B layers were connected by zig-zag B-B (red) chains that lie parallel with the layers along the $b$-axis and the connecting sites in the $\mathrm{B}$ honeycomb locate at $\mathrm{B}-\mathrm{B}$ bonds parallel with the $c$-axis. In $11-\mathrm{OsB}_{3}, \mathrm{~B}$ honeycomb layers are also connected by zig-zag $\mathrm{B}-\mathrm{B}$ (red) chains similar to $62-\mathrm{RuB}_{3}$, however, the connecting sites change to $\mathrm{B}-\mathrm{B}$ bonds that are at an angle with the $c$-axis but half of these sites remain unconnected due to the limit of the $\mathrm{B}$ content, giving rise to a distortion of the $\mathrm{B}$ honeycomb. As the $\mathrm{B}$ content increases further to form $59-\mathrm{OsB}_{4}$, a similar scenario of connections between $\mathrm{B}$ layers happens but all of the connecting sites that are similar to $11-\mathrm{OsB}_{3}$ are connected, leading to a much more symmetrical $\mathrm{B}$ honeycomb. For the $62-\mathrm{RuB}_{3}$, $11-\mathrm{OsB}_{3}$ and $59-\mathrm{OsB}_{4}$ phases, the coordination of $\mathrm{M}$ atoms bears a close resemblance to the $59-\mathrm{MB}_{2}$ structure, in which $M$ atoms nestle into boat-like $B$ atomic six-rings. For the 194-RuB ${ }_{4}$ structure (Fig. 3d), however, a 3D B network could not been found and the $\mathrm{B}$ (green and red B) layers that are comprised of two sub-layers of honeycomb B rings (Fig. 3h) are alternately stacking with $\mathrm{M}$ layers along the $c$-axis. A connection between the $\mathrm{B}$ layers is absent due to the large distance $(2.771 \AA)$ between them but the two B sub-layers are interconnected by short B-B bonds (1.685 Å and $1.895 \AA$ ).

\subsection{Relative stability}

To assess the thermodynamic stability of these Os and $\mathrm{Ru}$ phases, the formation enthalpy $\left(\Delta H_{\mathrm{f}}\right)$ was calculated and diagrams of the convex hull are constructed. A negative $\Delta H_{\mathrm{f}}$ for a structure provides inferences regarding the thermodynamic stability with respect to the elemental constituents. ${ }^{24}$ As shown in Fig. 4a, the negative formation enthalpy of $\mathrm{OsB}, \mathrm{Os}_{2} \mathrm{~B}_{3}$, $59-\mathrm{OsB}_{2}, 11-\mathrm{OsB}_{3}$ and $59-\mathrm{OsB}_{4}$ suggest that these phases could be synthesized at ambient conditions, which is confirmed by the experimental synthesis of $\mathrm{OsB}, \mathrm{Os}_{2} \mathrm{~B}_{3}, 59-\mathrm{OsB}_{2} \cdot{ }^{10}$ However, the positive values for the formation enthalpy of $\mathrm{Os}_{7} \mathrm{~B}_{3}$, $166-\mathrm{OsB}_{3}, 71$ - and $58-\mathrm{OsB}_{4}$ imply that they are thermodynamically unstable with respect to the initial reactants. Furthermore, the theoretical $\mathrm{WB}_{4}$-type $\mathrm{OsB}_{4}$ proposed earlier ${ }^{31}$ is also unstable as hinted by its large positive formation enthalpies (0.724 eV per atom). For $\mathrm{Ru}$ borides (Fig. 4b), the negative values of the formation energy of the $\mathrm{Ru}_{7} \mathrm{~B}_{3}, \mathrm{RuB}, \mathrm{Ru}_{2} \mathrm{~B}_{3}$ and $59-\mathrm{RuB}_{2}$ phases validate the feasibility of solid state synthesis in experiments. ${ }^{10,12}$ Moreover, 62- $\mathrm{RuB}_{3}$ and $194-\mathrm{RuB}_{4}$ also show the negative values of the formation energy, opening the possibility of phase formation by the usually solid synthesis at ambient conditions.

Since extra pressure in the synthesis process of a compound could enhance its thermodynamic stability or the reaction kinetics and thus promote its formation in the predicted configurations $^{32}$ and promotes the understanding of the stability of higher boron Os- and $\mathrm{Ru}-\mathrm{B}$ phases relative to lower boron 
(a)

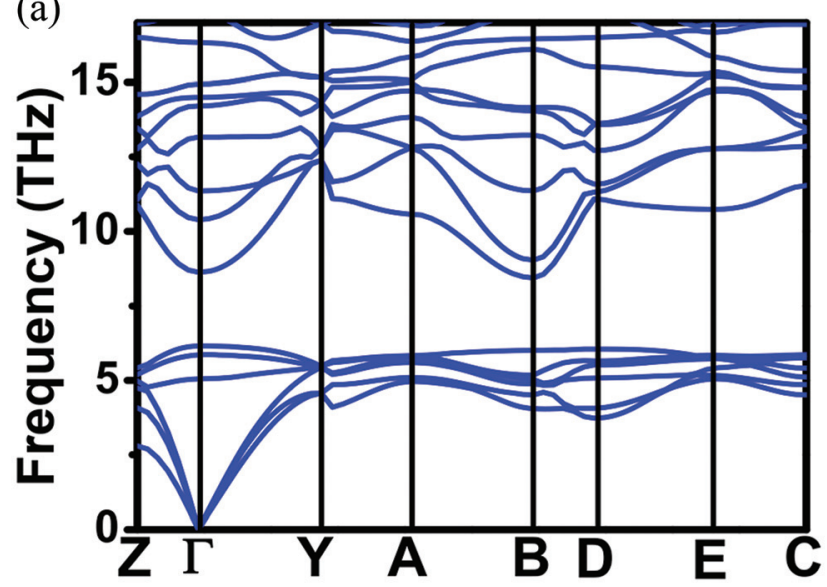

(c)

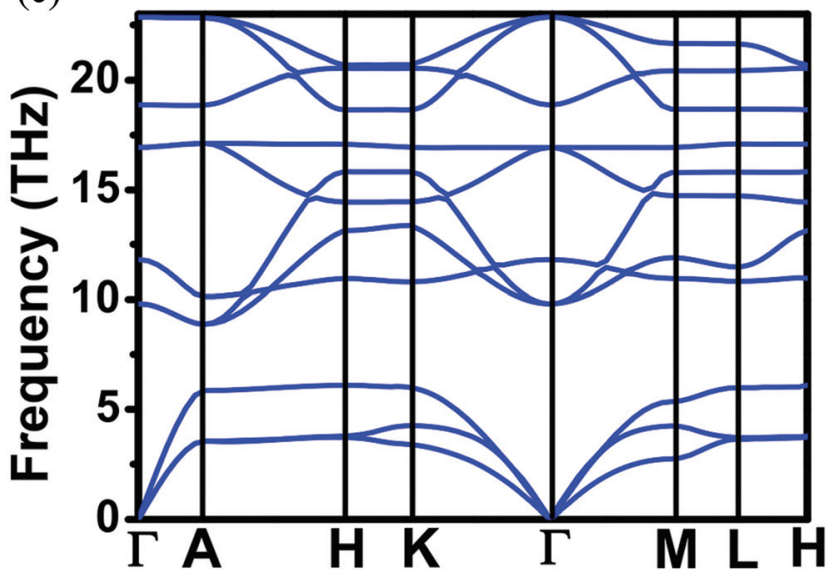

(b)

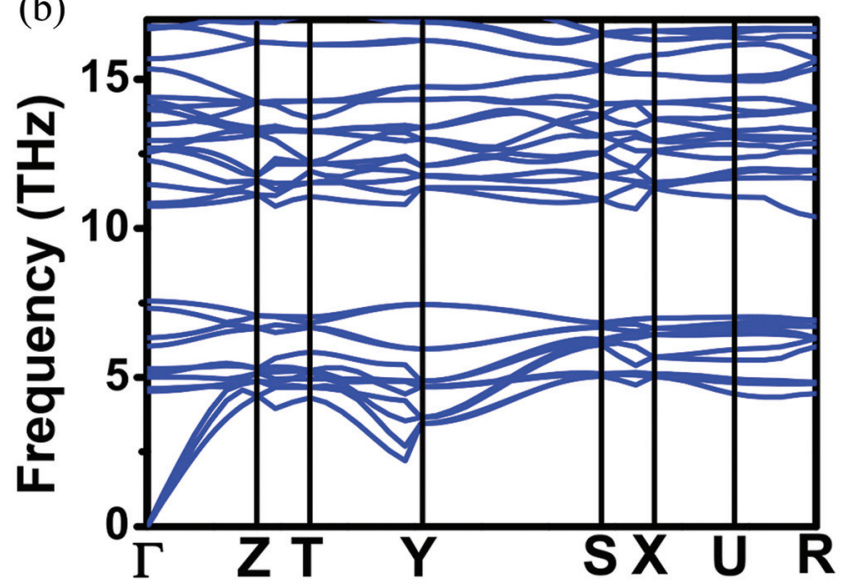

(d)

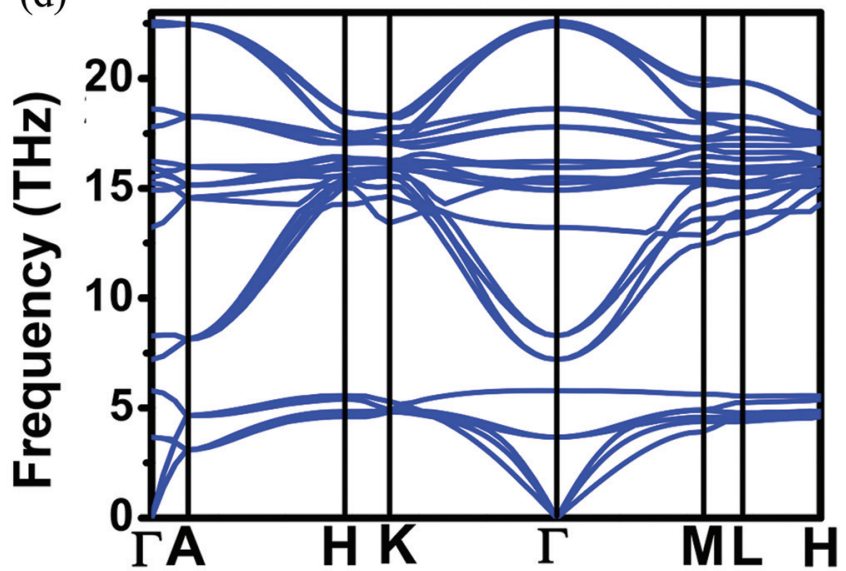

Fig. 2 Phonon dispersion for 62-RuB $3(a), 11-\mathrm{OsB}_{3}(\mathrm{~b}), 187-\mathrm{OsB}_{3}$ (c) and 194-RuB 4 (d).

(a)

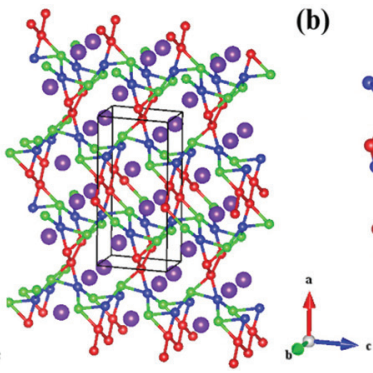

(e)

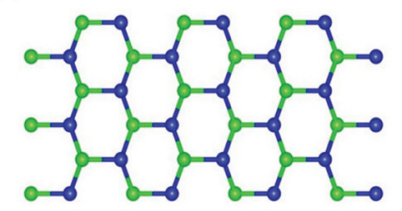

(f)
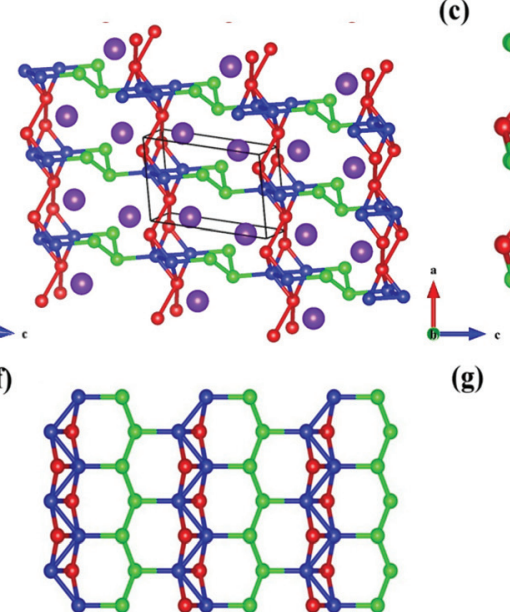

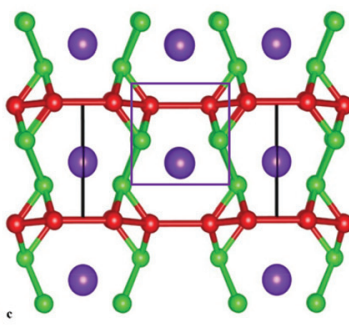

(g)

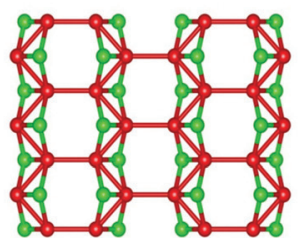

(d)

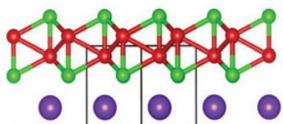

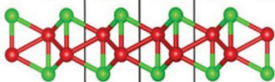

- $\odot \odot \bullet$

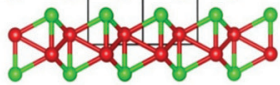

(h)

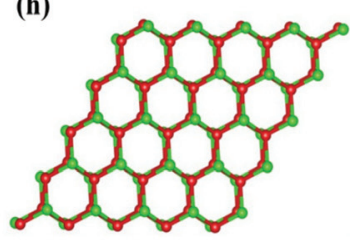

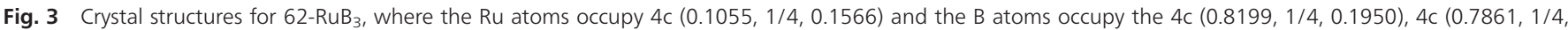

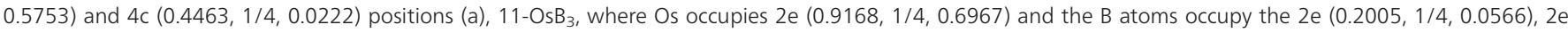

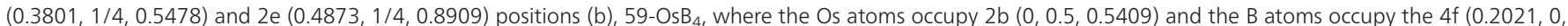

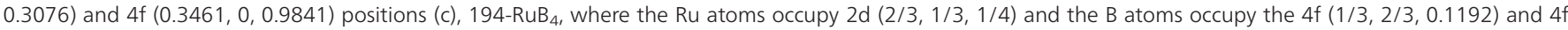

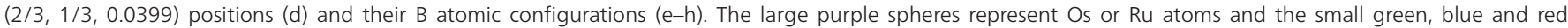
spheres represent B atoms. 

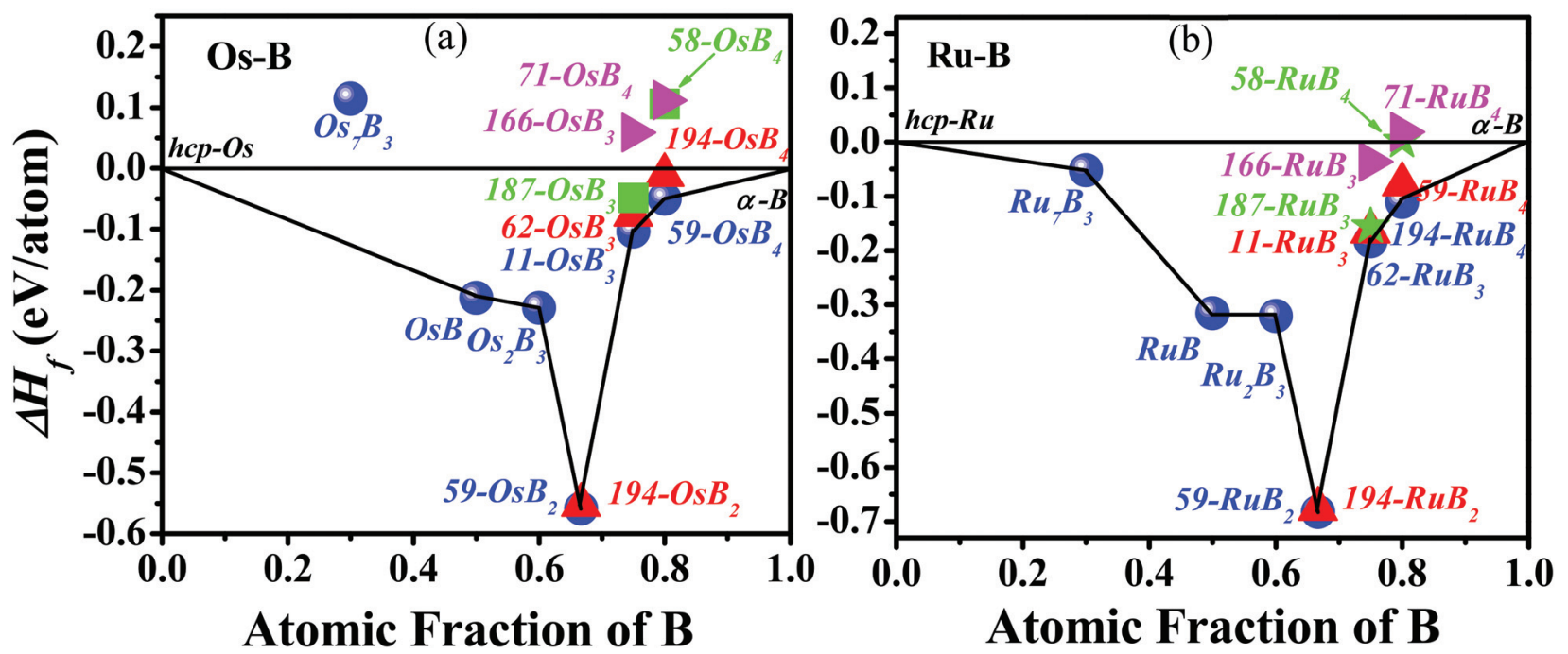

Fig. 4 Convex hulls of the Os-B system (a) and Ru-B system (b) at zero pressure.

phases within a system, we further calculated the enthalpy difference between each boride and the possible reactant compositions under 0-50 GPa at zero temperature. For example, for $11-\mathrm{OsB}_{3}$, the possible reactants of $\mathrm{Os}+3 \mathrm{~B}$, OsB $+2 \mathrm{~B}$, as well as 59- and $194-\mathrm{OsB}_{2}+\mathrm{B}$ were considered. Here, two polymorphs of boron, $\alpha-\mathrm{B}$ and $\gamma$-B were both considered at their pressure range, since $\gamma$-B is thermodynamically more favorable than any other known forms between 19 and $89 \mathrm{GPa} .{ }^{33}$ This notion has been confirmed by the phase transition from $\alpha$-B to $\gamma$-B at 19.3 GPa from Fig. 5, suggesting the credibility of our calculations.

All of the borides considered here are thermodynamically stable with respect to the pure metal and boron reactants under 0-50 GPa from Fig. 5. For $\mathrm{MB}_{2}$, $\mathrm{OsB}_{2}$ is more favorable than the mixtures of OsB and $\mathrm{Os}_{2} \mathrm{~B}_{3}+\alpha-\mathrm{B}$, consistent with the experimental result that $\mathrm{OsB}$ and $\mathrm{Os}_{2} \mathrm{~B}_{3}$ can yield $59-\mathrm{OsB}_{2}$ with additional $\mathrm{B}$ atoms at ambient conditions. ${ }^{9}$ Moreover, high pressure phase transition is identified for $59-\mathrm{OsB}_{2}\left(\mathrm{RuB}_{2}\right)$ at 8.9 (8.3) GPa, above which $194-\mathrm{OsB}_{2}\left(\mathrm{RuB}_{2}\right)$ is energetically more favorable. For $\mathrm{MB}_{3}$ and $\mathrm{MB}_{4}(\mathrm{M}=\mathrm{Os}$ and $\mathrm{Ru})$, the $\mathrm{MB}_{2}+$ $\mathrm{B}$ constituent in the entire range of the pressure is always favored energetically, indicating that the synthesis route of pure $\mathrm{M}+n \mathrm{~B}$ for $\mathrm{MB}_{3}$ and $\mathrm{MB}_{4}$ is inapplicable because the competitive phase of $\mathrm{MB}_{2}$ will appear first. However, alternative synthesis routes from low boron content borides and metal is suggested to be feasible, as illustrated in Fig. 5. For Os borides, the $11-\mathrm{OsB}_{3}$ phase can be synthesized by $\mathrm{OsB}+\alpha-\mathrm{B}$ above $1.3 \mathrm{GPa}$ or $\mathrm{Os}_{2} \mathrm{~B}_{3}+\alpha-\mathrm{B}$ above $47 \mathrm{GPa}$ and $59-\mathrm{OsB}_{4}$ may be obtained by OsB $+\alpha-B$ when exceeding $25 \mathrm{GPa}$. For Ru borides, $62-\mathrm{RuB}_{3}$ is found to be more energetically favorable than $\mathrm{Ru}_{2} \mathrm{~B}_{3}+\alpha-\mathrm{B}$ above $16 \mathrm{GPa}$ and $194-\mathrm{RuB}_{4}$ is more stable relative to $\mathrm{RuB}+\alpha$-B above $5.5 \mathrm{GPa}$ and $\mathrm{Ru}_{2} \mathrm{~B}_{3}+\alpha$-B exceeding $23 \mathrm{GPa}$. It is thus suggested that the combination of extra pressure and temperature could be more conductive to the phase formation of the $\mathrm{MB}_{3}$ and $\mathrm{MB}_{4}$ phases. Moreover, the enthalpy calculations suggest that the phase transitions between 11- and $187-\mathrm{OsB}_{3}$, 59- and $194-\mathrm{OsB}_{4}$, as well as 62- and $187-\mathrm{RuB}_{3}$ happens at $43.3 \mathrm{GPa}, 33.7 \mathrm{GPa}$ and $39.5 \mathrm{GPa}$, respectively. $194-\mathrm{RuB}_{4}$ remains stable in the studied pressure range.

\subsection{Mechanical properties}

Besides mechanical stability, elastic constants $\left(C_{i j}\right)$ (Table 1) can also be used to derive the elastic moduli and further predict theoretical hardness. The large value of $C_{44}$ for $62-\mathrm{RuB}_{3}(224 \mathrm{GPa})$ and $\mathrm{OsB}_{3}(244 \mathrm{GPa})$ indicates their stronger strength to resist shear deformation. Additionally, extremely large $C_{33}$ values are found for the $194-\mathrm{OsB}_{4}(900 \mathrm{GPa})$ and $194-\mathrm{RuB}_{4}(830 \mathrm{GPa})$ phases, much greater than that of $c$-BN $(773 \mathrm{GPa})$, suggesting their extremely high incompressibility along the $c$-axis. ${ }^{34}$ Furthermore, the $C_{11}, C_{22}$ and $C_{33}$ values of $62-\mathrm{RuB}_{3}, 62-\mathrm{OsB}_{3}$ and $59-\mathrm{OsB}_{4}$ are quite close to each other, thereby indicating their highly isotropic linear incompressibility.

The calculated bulk modulus, $B$, shear modulus, $G$, and Young's modulus, $E$, as listed in Table 2, as well as $C_{i j}$ in Table 1 are all in reasonable agreement with the available results, ${ }^{35,36}$ underlining the accuracy of our calculations. On moving from $59-\mathrm{OsB}_{2}, 11-\mathrm{OsB}_{3}$ to $59-\mathrm{OsB}_{4}$, the $B$ value decreases by $3.6 \%$ (11 GPa) and 3.3\% (10 GPa), respectively. Also, for both Os-B and Ru-B systems, there is no monotone trend of the calculated $B$ with VED (or boron content), i.e. $B$ indirectly correlates to its VED (or boron content). Similar conclusions could be also reached from the Re- $\mathrm{B}^{4}$ and $M o-\mathrm{B}^{7}$ systems. On the contrary, $G$ shows a different changing trend from $59-\mathrm{OsB}_{2}, 11-\mathrm{OsB}_{3}$ to $59-\mathrm{OsB}_{4}$, increasing by $26.2 \%$ (45 GPa) and $17 \%(31 \mathrm{GPa}$ ), respectively. This reveals that $G$ is more sensitive to the boron content than $B$, similar to the Os-C compounds. ${ }^{37}$ Moreover, $59-\mathrm{OsB}_{4}$ and $62-\mathrm{RuB}_{3}$ have maximum $G$ values (217 GPa and $185 \mathrm{GPa}$, respectively) and minimum $\nu$ 

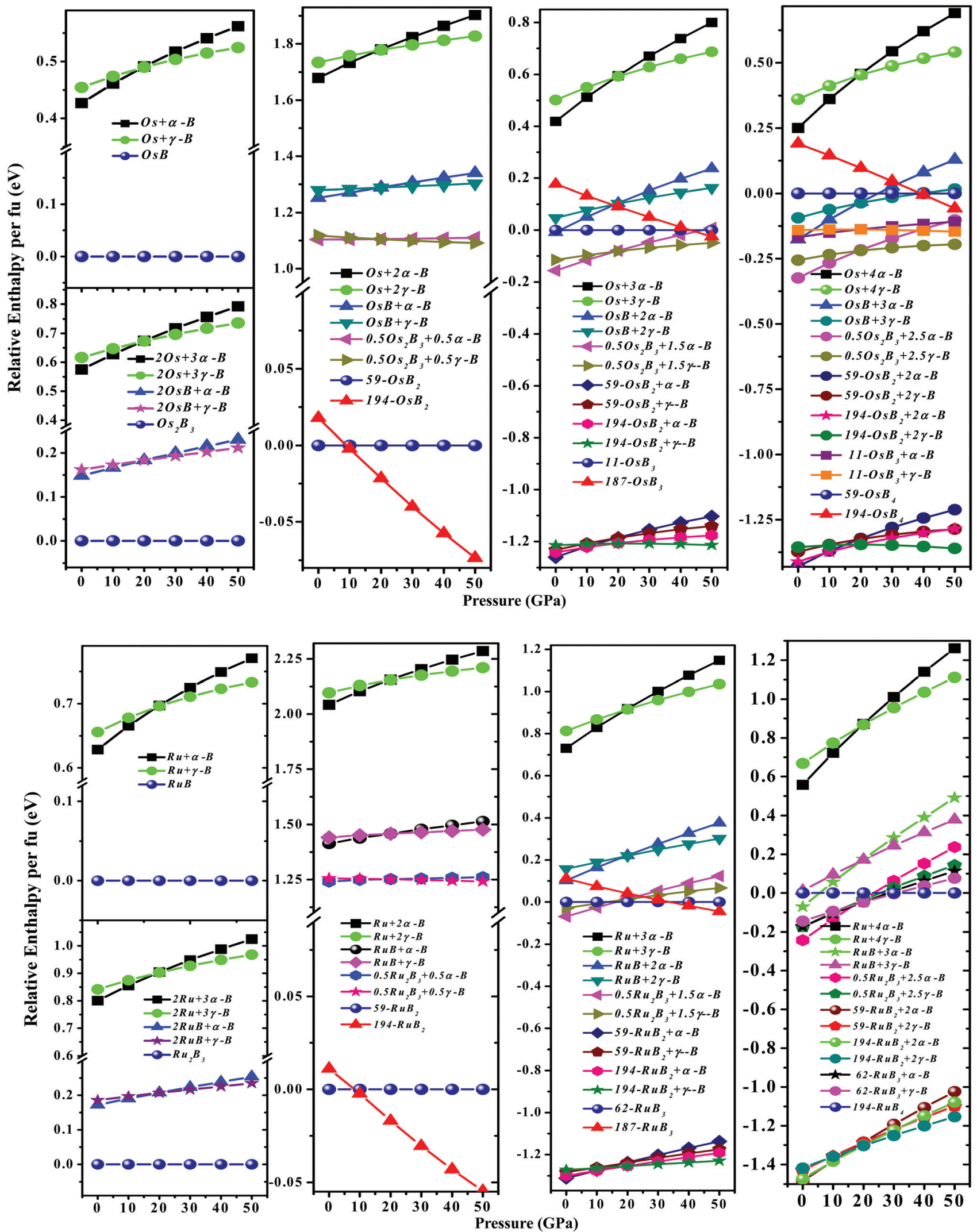

Fig. 5 Relative enthalpies between M-B (with stoichiometries of $1: 1,2: 3,1: 2,1: 3$, and $1: 4$ ) and the possible constituents under $0-50$ GPa. 
Table 2 Calculated valence electronic density (VED, e $\AA^{-3}$ ), bulk modulus, $B(\mathrm{GPa})$, shear modulus, $G(\mathrm{GPa})$, Young's modulus, $E$ (GPa), Poisson's ratio, $v$, Vickers hardness, $H_{v}(\mathrm{GPa})$, and elastic isotropic index $\left(A^{U}\right)$ for the Os-B and Ru-B compounds

\begin{tabular}{|c|c|c|c|c|c|c|c|c|c|}
\hline & & VED & $B$ & $G$ & $G / B$ & $E$ & $v$ & $H_{\mathrm{v}}$ & $A^{\mathrm{U}}$ \\
\hline \multirow[t]{2}{*}{$59-\mathrm{OsB}_{4}$} & GGA & \multirow{2}{*}{0.4869} & 293 & 217 & \multirow{2}{*}{0.741} & 522 & 0.203 & 31.3 & \multirow[t]{2}{*}{0.538} \\
\hline & $\mathrm{GGA}^{a}$ & & 294 & 218 & & 524 & 0.204 & 28 & \\
\hline \multirow[t]{3}{*}{$59-\mathrm{OsB}_{2}$} & GGA & \multirow[t]{3}{*}{0.5048} & 304 & 172 & 0.566 & \multirow[t]{3}{*}{434} & \multirow[t]{3}{*}{0.262} & 21.9 & 0.653 \\
\hline & $\mathrm{GGA}^{b}$ & & 306 & 179 & 0.585 & & & $17.8-34.8^{c}$ & 1.012 \\
\hline & $\mathrm{GGA}^{d}$ & & 307 & 168 & 0.547 & & & & \\
\hline $\mathrm{Os}_{2} \mathrm{~B}_{3}$ & GGA & 0.5329 & 331 & 201 & 0.607 & 501 & 0.247 & & 0.25 \\
\hline $\mathrm{Os}_{7} \mathrm{~B}_{3}$ & GGA & 0.5467 & 338 & 103 & 0.305 & 281 & 0.362 & & \\
\hline $194-\mathrm{RuB}_{4}$ & GGA & 0.5037 & 281 & 175 & 0.623 & 435 & 0.242 & 23.5 & 0.408 \\
\hline $62-\mathrm{RuB}_{3}$ & GGA & 0.5054 & 267 & 185 & 0.693 & 451 & 0.219 & 26.3 & 0.259 \\
\hline \multirow{2}{*}{$59-\mathrm{RuB}_{2}$} & GGA & \multirow[t]{2}{*}{0.516} & 279 & 174 & 0.624 & \multirow[t]{2}{*}{432} & \multirow[t]{2}{*}{0.242} & 23.4 & \multirow[t]{2}{*}{0.372} \\
\hline & $\mathrm{GGA}^{b}$ & & 280 & 175 & 0.625 & & & $14.4-24.2^{e}$ & \\
\hline $\mathrm{Ru}_{2} \mathrm{~B}_{3}$ & GGA & 0.518 & 296 & 178 & 0.601 & 445 & 0.25 & & 0.373 \\
\hline
\end{tabular}

${ }^{a}$ Ref. $14 .{ }^{b}$ Ref. $36 .{ }^{c}$ Ref. 10 and 39. ${ }^{d}$ Ref. $35 .{ }^{e}$ Ref. 10 and 40.

(0.203 and 0.22, respectively), which suggests that strong directional bonding exists in these borides and thus could be potentially hard materials. Based on the empirical correlation $\left(H_{\mathrm{v}}=2\left(k^{2} G\right)^{0.583}-3\right),{ }^{38}$ we have estimated the Vickers hardness, $H_{\mathrm{v}}$, of the $\mathrm{MB}_{3}$ and $\mathrm{MB}_{4}$ phases together with $\mathrm{MB}_{2}$. The calculated $H_{\mathrm{v}}$ values of $59-\mathrm{OsB}_{2}$ and $\mathrm{RuB}_{2}$ are in satisfactory agreement with previous experimental results. ${ }^{10,39,40}$ Also, the estimated $H_{\mathrm{v}}$ for $59-\mathrm{OsB}_{4}$ of $31.3 \mathrm{GPa}$, is consistent with the available theoretical results (28 GPa) according to the Šimůnek model. ${ }^{14}$ Besides $59-\mathrm{OsB}_{4}$, the boron-rich $11-\mathrm{OsB}_{3}, 62-\mathrm{OsB}_{3}$ and $62-\mathrm{RuB}_{3}$ also show larger hardness values $(25.1,28.2$ and $26.3 \mathrm{GPa}$, respectively) than that of $59-\mathrm{OsB}_{2}$ and $\mathrm{RuB}_{2}$, implying that the higher boron-content compounds may be more likely to be potential hard materials or superhard films. On the other hand, the $62-\mathrm{OsB}_{3}$ and $59-\mathrm{OsB}_{4}\left(59-\mathrm{RuB}_{4}\right)$ phases exhibit greater hardness compared with $11-\mathrm{OsB}_{3}$ and $194-\mathrm{OsB}_{4}$ (194-RuB ${ }_{4}$ ), respectively. Thereby, it can be safely concluded that, besides the boron content, atomic configuration is another important factor to determine the mechanical property of a material.

The elastic anisotropy of materials has an important implication in engineering science since it is highly correlated with the possibility to induce microcracks in materials. ${ }^{41}$ The elastic anisotropy of the borides considered here is estimated based on the universal elastic anisotropy index of $A^{\mathrm{U}}=$ $5 G^{\mathrm{V}} / G^{\mathrm{R}}+B^{\mathrm{V}} / B^{\mathrm{R}}-6,{ }^{42}$ where $B$ and $G$ denote the bulk and shear modulus and the superscripts $\mathrm{V}$ and $\mathrm{R}$ represent the Voigt and Reuss approximations. The calculated anisotropic indexes for the Os and $\mathrm{Ru}$ borides are listed in Table 2. It is noted that the anisotropy of the Os and Ru borides shows entirely different trends. In the Os-B system, the $59-\mathrm{OsB}_{2}$ phase is significantly anisotropic, which explains the big difference in the calculated ideal strength, ${ }^{43}$ and $59-\mathrm{OsB}_{4}$ and $11-\mathrm{OsB}_{3}$ also exhibit some anisotropy to a certain degree. However, in the $\mathrm{Ru}-\mathrm{B}$ system, $194-\mathrm{RuB}_{4}$ shows relatively strong anisotropy, even greater than layered stacking $59-\mathrm{RuB}_{2}$, and $62-\mathrm{RuB}_{3}$ has a superior elastic isotropic character, as indicated by its smaller $A^{\mathrm{U}}$ value. ${ }^{44}$

\subsection{Electronic structures}

To address the general features of the stability and mechanical behavior of these borides, the DOSs and corresponding COHP are presented in Fig. 6. We can see that all the predicted $\mathrm{MB}_{3}$ and $\mathrm{MB}_{4}$ compounds show non-zero DOS values at the Fermi level $\left(N\left(E_{\mathrm{F}}\right)\right)$, exhibiting metallic behavior. Also, the M-d and B-2p states of all the considered borides overlap below the Fermi level, indicating the hybridization between the M-d and $\mathrm{B}-2 \mathrm{p}$ states and thus the presence of strong $\mathrm{M}-\mathrm{B}$ bonding character. Compared to $59-\mathrm{OsB}_{2}$, a more extended overlap between the Os-d and $\mathrm{B}-2 \mathrm{p}$ orbital in the $11-\mathrm{OsB}_{3}$ phase indicates a relatively stronger covalent $\mathrm{M}-\mathrm{B}$ bond. This can also be confirmed by the greater Mulliken overlap population (MOP) values of $11-\mathrm{OsB}_{3}(0.57$ and 0.3$)$ than $59-\mathrm{OsB}_{2}(0.51$ and 0.15$)$ because a greater MOP value corresponds to a higher degree of covalency in the bonding. ${ }^{45}$ With the enhancement of the boron content, the Fermi level of $59-\mathrm{OsB}_{4}$ is found to locate in the pseudogap, suggesting high stability. Additionally, the calculated COHP shows that the Os-B interaction could be identified as the main functional bonding that stabilized $P \overline{6} \mathrm{~m} 2 \mathrm{OsB}$ in view of its non-antibonding states found below the Fermi level. ${ }^{10}$ However, with the increase of the boron content, the appearance of weak antibonding $\mathrm{M}-\mathrm{B}$ interactions in $\mathrm{MB}_{2}, \mathrm{MB}_{3}$ and $\mathrm{MB}_{4}$ may have a reverse influence on the stability. Fortunately, the relatively strong B-B bonding begins to form, as revealed by the positive -iCOHP values, and none of them show the antibonding interaction below the Fermi level, which, together with the reserved Os-B bonding, greatly compensates for the loss of stability from the Os-Os bonding. Furthermore, for $59-\mathrm{OsB}_{4}$, the weak antibonding $(-0.135 \mathrm{eV}$ per cell for the OsOs interaction) restrains the rapid increase in the mechanical 

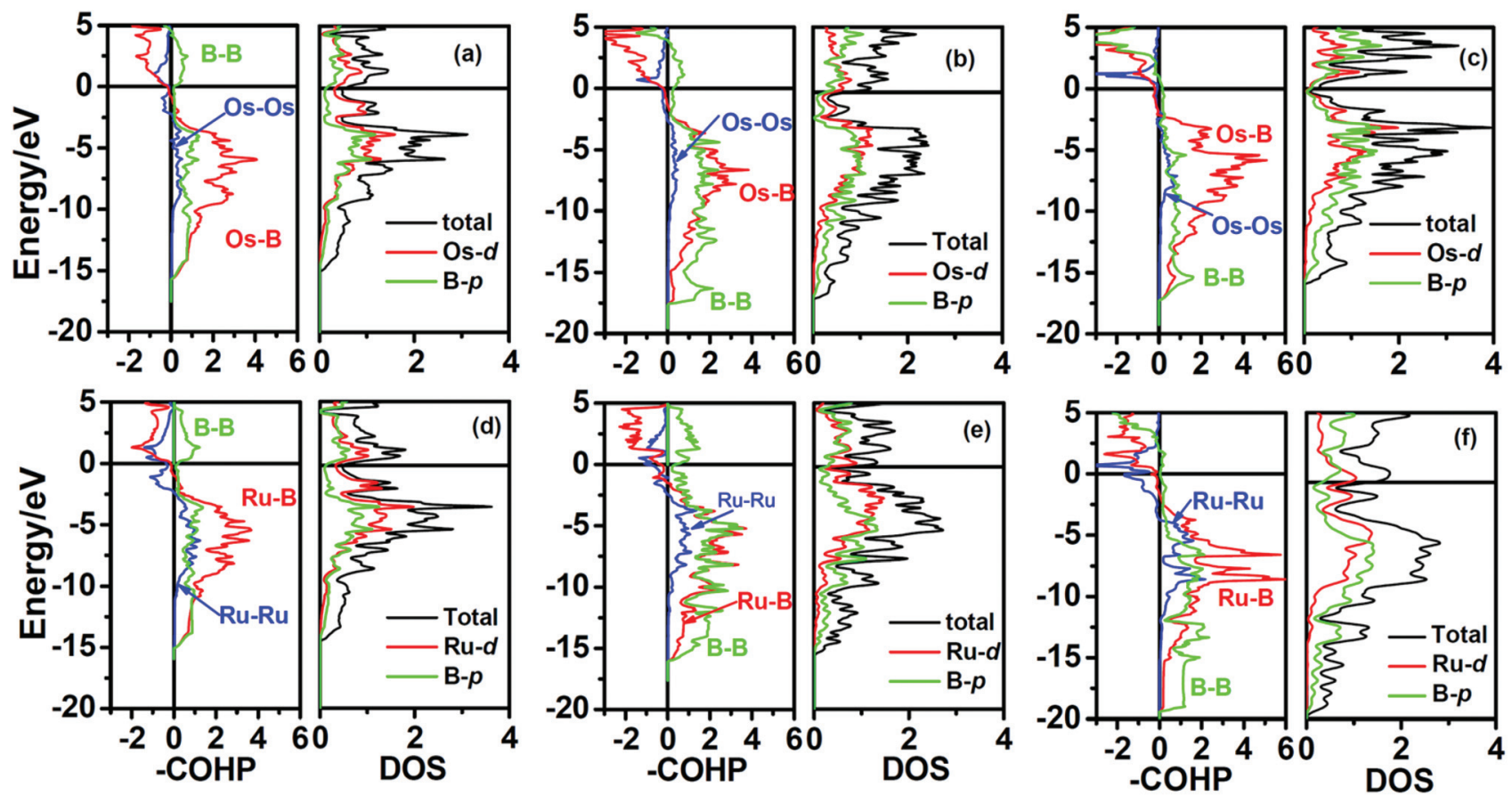

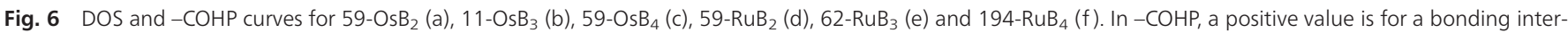
action while a negative value is for an antibonding state.

properties, whereas for $194-\mathrm{RuB}_{4}$, the distinct anti-bonding $(-0.95 \mathrm{eV}$ per cell for $\mathrm{Ru}-\mathrm{Ru}$ interaction) tends to weaken the mechanical properties compared with $\mathrm{RuB}_{3}$.

\section{Conclusion}

The structural features, relative stability, possible synthesis routes, electronic structures and mechanical properties of Os$\mathrm{B}$ and $\mathrm{Ru}-\mathrm{B}$ systems were investigated via the first-principle techniques. The convex hull curves suggest that five Os-B phases (OsB, $\mathrm{Os}_{2} \mathrm{~B}_{3}, 59-\mathrm{OsB}_{2}, 11-\mathrm{OsB}_{3}$ and $59-\mathrm{OsB}_{4}$ ) and six $\mathrm{Ru}-\mathrm{B}$ phases $\left(\mathrm{Ru}_{7} \mathrm{~B}_{3}, \mathrm{RuB}, \mathrm{Ru}_{2} \mathrm{~B}_{3}, 59-\mathrm{RuB}_{2}, 62-\mathrm{RuB}_{3}\right.$ and 194$\mathrm{RuB}_{4}$ ) were thermodynamically stable at zero pressure. The total energy and phonon dispersion results indicate that the possible ground state structures at zero pressure are the $P 2_{1} / m$, Pnma and $P 6_{3} / m m c$ structures for $\mathrm{OsB}_{3}, \mathrm{RuB}_{3}$ and $\mathrm{RuB}_{4}$, respectively. Furthermore, a phase transition was identified between 59- and 194- $\mathrm{OsB}_{2}\left(\mathrm{RuB}_{2}\right), 11$ - and $187-\mathrm{OsB}_{3}, 62-$ and $187-\mathrm{RuB}_{3}$, as well as $59-$ and $194-\mathrm{RuB}_{4}$. Among the Os-B and $\mathrm{Ru}-\mathrm{B}$ compounds, $59-\mathrm{OsB}_{4}$ and $62-\mathrm{RuB}_{3}$ has the largest shear moduli, the lowest Poisson's ratio and an estimated Vickers hardness of 26.3 and $31.3 \mathrm{GPa}$, respectively. The origin of the excellent mechanical performance of $59-\mathrm{OsB}_{4}$ and $62-\mathrm{RuB}_{3}$, evidenced by the electronic properties and COHP, is the formation of directional boron-boron networks together with strong metal-boron bonds. Relative enthalpy calculations suggest that synthesis at high pressure is an applicable method to obtain osmium and ruthenium tri- and tetraborides.

\section{Acknowledgements}

Huiyang Gou gratefully acknowledges the financial support of the Alexander von Humboldt Foundation. The partial support from the National Natural Science Foundation of China (NSFC) under Grants No. 51201148 is also greatly appreciated. Li-Min Wang thanks the financial support Program for New Century Excellent Talents in University (NCET-09-0118).

\section{References}

1 A. L. Ivanovskii, Prog. Mater. Sci., 2012, 57, 184.

2 R. B. Kaner, J. J. Gilman and S. H. Tolbert, Science, 2005, 308, 1268.

3 H. Y. Chung, M. B. Weinberger, J. B. Levine, A. Kavner, J. M. Yang, S. H. Tolbert and R. B. Kaner, Science, 2007, 316, 436.

4 H. Y. Gou, Z. B. Wang, J. W. Zhang, S. T. Yan and F. M. Gao, Inorg. Chem., 2009, 48, 581.

5 E. J. Zhao, J. P. Wang, J. Meng and Z. J. Wu, J. Comput. Chem., 2010, 31, 1904.

6 E. J. Zhao, J. Meng, Y. M. Ma and Z. J. Wu, Phys. Chem. Chem. Phys., 2010, 12, 13158.

7 M. G. Zhang, H. Wang, H. B. Wang, T. Cui and Y. M. Ma, J. Phys. Chem. C, 2010, 114, 6722.

8 B. Wang, X. Li, Y. X. Wang and Y. F. Tu, J. Phys. Chem. C, 2011, 115, 21429. 
9 R. W. Cumberland, M. B. Weinberger, J. J. Gilman, S. M. Clark, S. H. Tolbert and R. B. Kaner, J. Am. Chem. Soc., 2005, 127, 7264.

10 Q. F. Gu, G. Krauss and W. Steurer, Adv. Mater., 2008, 20, 3620.

11 B. P. T. Fokwa, P. R. N. Misse, M. Gilleßen and R. Dronskowski, J. Alloys Compd., 2010, 489, 339.

12 B. Aronsson, Acta Chem. Scand., 1959, 13, 109.

13 Z. W. Ji, C. C. Hu, D. H. Wang, Y. Zhong, J. Yang, W. Q. Zhang and H. Y. Zhou, Acta Mater., 2012, 60, 4208.

14 M. G. Zhang, H. Y. Yan, G. T. Zhang and H. Wang, J. Phys. Chem. C, 2012, 116, 4293.

15 Y. C. Wang, J. Lv, L. Zhu and Y. M. Ma, Phys. Rev. B: Condens. Matter Mater. Phys., 2010, 82, 094116.

16 H. Y. Niu, J. Q. Wang, X. Q. Chen, D. Z. Li, Y. Y. Li, P. Lazar, R. Podloucky and A. N. Kolmogorov, Phys. Rev. B: Condens. Matter Mater. Phys., 2012, 85, 144116.

17 L. Fang, H. Yang, X. Y. Zhu, G. Wu, Z. S. Wang, L. Shan, C. Ren and H. H. Wen, Phys. Rev. B: Condens. Matter Mater. Phys., 2009, 79, 144509.

18 T. Lundstrom, Ark. Kemi, 1969, 30, 115.

19 R. Rühl and W. Jeitschko, Acta Crystallogr., Sect. B: Struct. Crystallogr. Cryst. Chem., 1982, 38, 2784.

20 A. N. Kolmogorov, S. Shah, E. R. Margine, A. F. Bialon, T. Hammerschmidt and R. Drautz, Phys. Rev. Lett., 2010, 105, 217003.

21 P. A. Ramans and M. P. Krug, Acta Crystallogr., 1966, 20, 313.

22 M. Segall, P. Lindan, M. Probert, C. Pickard, P. Hasnip, S. Clark and M. Payne, J. Phys.: Condens. Matter, 2002, 14, 2717.

23 J. P. Perdew and Y. Wang, Phys. Rev. B: Condens. Matter, 1992, 45, 13244.

24 D. Vanderbilt, Phys. Rev. B: Condens. Matter, 1990, 41, 7892.

25 G. L. Weerasinghe, R. J. Needs and C. J. Pickard, Phys. Rev. B: Condens. Matter Mater. Phys., 2011, 84, 174110.

26 R. Hill, Proc. Phys. Soc., London, Sect. A, 1952, 65, 349.

27 R. Dronskowski and P. E. Blochl, J. Phys. Chem., 1993, 97, 8617.
28 M. Born, Math. Proc. Cambridge Philos. Soc., 1940, 36, 160.

29 M. Born and K. Huang, Dynamical Theory of Crystal Lattices, Clarendon, Oxford, 1956.

30 D. Wallace, Thermodynamics of Crystals, Wiley, New York, 1972.

31 M. Wang, Y. W. Li, T. Cui, Y. M. Ma and G. T. Zou, Appl. Phys. Lett., 2008, 93, 101905.

32 A. F. Bialon, T. Hammerschmidt, R. Drautz, S. Shah, E. R. Margine and A. N. Kolmogorov, Appl. Phys. Lett., 2011, 98, 081901.

33 A. R. Oganov, J. H. Chen, C. Gatti, Y. Z. Ma, Y. M. Ma, C. W. Glass, Z. X. Liu, T. Yu, O. O. Kurakevych and V. L. Solozhenko, Nature, 2009, 457, 863.

34 X. F. Hao, Y. H. Xu, Z. J. Wu, D. F. Zhou, X. J. Liu, X. Q. Cao and J. Meng, Phys. Rev. B: Condens. Matter Mater. Phys., 2006, 74, 224112.

35 H. Y. Gou, L. Hou, J. W. Zhang, H. Li, G. F. Sun and F. M. Gao, Appl. Phys. Lett., 2006, 88, 221904.

36 J. Wang and Y. J. Wang, J. Appl. Phys., 2009, 105, 083539.

37 X. P. Du and Y. X. Wang, J. Appl. Phys., 2010, 107, 053506 .

38 X. Q. Chen, H. Y. Niu, D. Z. Li and Y. Y. Li, Intermetallics, 2011, 19, 1275.

39 H. Y. Chung, J. M. Yang, S. H. Tolbert and R. B. Kaner, J. Mater. Res., 2008, 23(6), 1797.

40 M. B. Weinberger, J. B. Levine, H. Y. Chung, R. W. Cumberland, H. I. Rasool, J. M. Yang, R. B. Kaner and S. H. Tolbert, Chem. Mater., 2009, 21, 1915.

41 P. Ravindran, L. Fast, P. A. Korzhavyi, B. Johnnsson, J. Wills and O. Eriksson, J. Appl. Phys., 1998, 84, 4891.

42 S. I. Ranganathan and M. Ostoja-Starzewski, Phys. Rev. Lett., 2008, 101, 055504.

43 J. Yang, H. Sun and C. F. Chen, J. Am. Chem. Soc., 2008, 130, 7200 .

44 M. D. Segall, R. Shah, C. J. Pickard and M. C. Payne, Phys. Rev. B: Condens. Matter, 1996, 54, 16317.

45 A. Knappschneider, C. Litterscheid, J. Kurzman, R. Seshadri and B. Albert, Inorg. Chem., 2011, 50, 10540. 